\title{
HUBUNGAN LAMA PEMAKAIAN KONTRASEPSI SUNTIK YANG MENGANDUNG HORMON DEPO MEDROXY PROGESTERON ASETAT (DMPA) DENGAN GANGGUAN SIKLUS MENSTRUASI DI WILAYAH KERJA PUSKESMAS PAGAMBIRAN TAHUN 2016.
}

\author{
Defi Yulita ${ }^{1}$ \\ ${ }^{1}$ AKBID Alifah, Jl. Khatib Sulaiman No. 52 B, Padang, 25000, Indonesia \\ Email: defi_knu@yahoo.com
}

\begin{abstract}
ABSTRAK
Berdasarkan data dari BKKBN (2010) bahwa penggunaan kontrasepsi suntik mempunyai efek samping pada wanita yaitu perubahan pola perdarahan haid, seperti hipermenorea $6,67 \%$, hipermenorea $5 \%$, oligomenorea $50 \%$, polimenorea $10,55 \%$, mendapatkan prevalensi amenoria primer sebanyak $5,3 \%$, amenorea sekunder $18 \%$, dan gangguan campuran sebanyak 15,8\%. Tujuan penelitian ini untuk mengetahui Hubungan lama pemakaian alat kontrasepsi suntik yang mengandung hormon Depo medroxy progesteron asetat (DMPA) dengan gangguan siklus menstruasi pada akseptor yang menggunakan kontrasepsi DMPA di Wilayah Kerja Puskesmas Pangambiran Kota Padang Tahun 2016. Jenis penelitian ini adalah analitik dengan desain penelitian cross sectional dengan populasi seluruh akseptor suntik yang mengandung hormon DMPA berjumlah 45 orang. Seluruh anggota populasi di jadikan subjek penelitian. Pengumpulan data di lakukan dengan memberikan kuesioner dan wawancara pada akseptor suntik DMPA. Pengolahan data melalui tahapan editing, coding, entry dan cleaning. Analisis data menggunakan, analisis univariat dan bivariat. Uji hipotesis menggunakan uji chi-square pada $\propto=0,05$. Hasil penelitian didapatkan, sebagian besar $(68,9 \%)$ ibu menggunakan kontrasepsi suntik DMPA lebih dari 6 bulan. Sebagian besar $(86,7 \%)$ ibu mengalami gangguan menstruasi. Terdapat hubungan bermakna antara lama penggunaan alat kontrasepsi suntik yang mengandung hormon DMPA dengan gangguan siklus menstruasi $(\mathrm{P}=0,008)$. Berdasarkan hasil penelitian ini, disarankan bagi tenaga kesehatan untuk menyediakan sarana informasi tentang alat kontrasepsi suntik secara menyeluruh sehingga calon akseptor KB maupun bukan calon akseptor KB memahami secara utuh tentang segala hal yang berhubungan dengan kontrasepsi suntik.
\end{abstract}

\section{Kata Kunci : Kontrasepsi, Menstruasi}

\section{ABSTRACT}

Based on data from the BKKBN (2010) that the use of injectable contraceptives have side effects women that changes in menstrual bleeding patterns, such as hipermenorea $6.67 \%$, hipermenorea $5 \%, 50 \%$ oligomenorrhea, polimenorea $10.55 \%$, gaining prevalence of primary amenoria $5,3 \%, 18 \%$ secondary amenorrhea, and disruption of a mixture $15.8 \%$. The purpose this study to determine the relationship duration of use injectable contraceptive Depo Medroxy containing the hormone progesterone acetate (DMPA) with menstrual cycle disorders acceptors use contraceptive DMPA in Puskesmas Pangambiran Kota Padang 2016. This type research is analytic with cross sectional study design with the entire population acceptor syringe containing the hormone DMPA 45 people. All members of the population made in the research subjects. The data collection is done by questionnaire and interviews on injectable DMPA acceptors. Data processing through the stages of editing, coding, entry and cleaning. Analysis of the data used, univariate and bivariate analysis. Test the hypothesis using chi-square test at $\alpha=0.05$. The result showed, the majority (68.9\%) of mothers using the injected contraceptive DMPA more than 6 months, $(86.7 \%)$ women experience menstrual disorders. There is a significant relationship between duration of use injectable contraceptives containing the hormone DMPA with menstrual cycle disorders $(\mathrm{P}=0.008)$. Based on these results, it is recommended for health workers to provide a means of information about the injectable contraceptive thoroughly so prospective acceptors and non-acceptors candidate gaining a full understanding of all matters related to injectable contraceptives. 


\section{PENDAHULUAN}

Salah satu masalah terpenting yang dihadapi oleh negara berkembang, seperti di Indonesia yaitu ledakan penduduk. Ledakan penduduk mengakibatkan laju pertumbuhan penduduk yang pesat hal ini karena minimnya pengetahuan serta pola budaya pada masyarakat setempat. Untuk mengatasi permasalahan tersebut pemerintah Indonesia telah menerapkan program Keluarga Berencana $(\mathrm{KB})$ yang dimulai sejak tahun 1968 dengan mendirikan LKBN (Lembaga Keluarga Berencana Nasional) yang kemudian dalam perkembangannya menjadi BKKBN (Badan Koordinasi Keluarga Berencana Nasional). Gerakan keluarga Berencana Nasional bertujuan untuk mengontrol laju pertumbuhan penduduk dan juga untuk meningkatkan kualitas sumber daya manusia (Saifuddin, 2008).

Visi keluarga Berencana Nasional adalah "Keluarga Berkualitas". Keluarga yang berkualitas adalah keluarga yang sejahtera, sehat, maju, mandiri, memiliki jumlah yang ideal, berwawasan kedepan, bertanggung jawab, harmonis dan bertaqwa kepada Tuhan Yang Maha Esa. Misinya sangat menekankan pentingnya upaya menghormati hak-hak reproduksi sebagai upaya integral dalam meningkatkan kualitas keluarga (Sarwono, 2006).

Permasalahan kesehatan reproduksi masih banyak sekali yang harus dikaji, tidak hanya tentang organ reproduksi saja tetapi ada beberapa aspek, salah satunya adalah kontrasepsi. Saat ini tersedia banyak metode atau alat kontrasepsi meliputi: IUD, suntik, pil, implant, kontap, kondom. (BKKBN, 2010). Salah satu kontrasepsi yang populer di Indonesia adalah kontrasepsi suntik. Kontrasepsi suntik yang digunakan adalah mengandung hormon Depo Medroksi Progesteron Acetat (DMPA) dan hormon progesteron estrogen.

Kontrasepsi suntik memiliki efek berbagai macam efek samping diantaranya gangguan pola haid seperti amenorrhea, menoragia dan muncul bercak (spotting), sakit kepala, jantung berdebar-debar, efek metabolik dan peningkatan berat badan (Hartanto, 2006).

Menurut data dari Kepala Badan Koordinasi Keluarga Berencana (BKKBN), jumlah PUS di Kota Padang sebanyak 128.884 orang. Pemakai kontrasepsi IUD sebanyak 15.522 akseptor, MOP sebanyak 45 akseptor, MOW sebanyak 3.819 akseptor, implant sebanyak 6.162 akseptor, suntik sebanyak 46.233 akseptor, kondom sebanyak 2.564 akseptor dan pil sebanyak 19.609 akseptor. Target kerja BKKBN tahun 2010 berkisar 86,637 akseptor dan target yang tercapai sebanyak 93,954 akseptor. Dapat dilihat bahwa pada tahun 2010 BKKBN dapat melebihi target sebanyak 108,45\%. Sehingga dapat disimpulkan akseptor KB meningkat pada tahun 2010 (BKKBN,2010)

Pencapaian peserta KB aktif semua metode kontrasepsi pada tahun 2011 di provinsi Sumatera Barat sebanyak 13.966 yang terdiri atas 5.701 (47.4\%) peserta suntik, peserta pil 3.170 (26.4\%), peserta AKDR (Alat Kontrasepsi Dalam Rahim) sebanyak $611(5,1 \%)$, peserta implant sebanyak 744 (6.2\%), peserta MOP (Medis Operasi Pria) dan peserta MOW (Medis Operasi Wanita) sebanyak 591 (5\%), peserta kondom sebanyak $1.203(10 \%)$. Pencapaian tertinggi pada suntikan $(47.4 \%)$ dan pencapaian terendah pada MOP dan MOW (5\%). (Profil Dinas Kesehatan Kota Sumatra Barat, 2011).

Pencapaian peserta KB aktif metode kontrasepsi suntik di setiap kecamatan di kota padang pada tahun 2011 terdiri dari kecamatan Bungus 5 (26,3\%), Padang Timur 307 (21,6\%), Padang Barat 286 (56,2\%), Padang Utara 150 $(64,3 \%)$, Koto Tangah 709 (60,7\%), Padang Selatan $263(48,2 \%)$, Lubuk Begalung 312 (77,4\%), Nanggalo 285 (32,8\%), Pauh 74 (49,0\%), Lubuk Kilangan 1.080 (61,0\%). (Profil Dinas Kesehatan Kota Padang tahun 2015). Dari 11 kecamatan di atas, Kecamatan Lubuk Begalung merupakan pencapaian tertinggi metode kontrasepsi suntik yaitu $(77,4 \%)$ di Puskesmas Pengambiran.

Wanita yang menggunakan kontrasepsi suntik banyak yang mengeluhkan terjadi perubahan pola perdarahan haid. Akibat tidak adanya haid menyebabkan gangguan psikologis pada ibu karena sewaktu-waktu kehamilan dapat terjadi (Saifudin, 2006). Pendapat lain mengatakan sebagian ibu menganggap darah haid yang keluar tersebut dapat menimbulkan gangguan sakit kepala dan perut kembung (Hanafi, 2003).

Suntik KB mempunyai efek samping seperti hipermenorea (haid yang berlebihan) $6,67 \%$ hipomenorea (haid yang pendek dari biasanya) $5 \%$,oligomenorea (siklus haid yang lebih panjang) $50 \%$, polimenorea (siklus haid yang lebih pendek) 10,55, mendapatkan pravalensi amenorea primer sebnyak 5,3\%, amenorea sekunder $18 \%$, dan gangguan campuran sebanyak 15,8\%. (BKKBN, 2004).

Kontrasepsi suntik tidaklah asing lagi bagi masyarakat, akseptor KB banyak menggunakan metode suntik. Metode suntik yang digunakan 
salah satunya adalah depo medroxy progesterone asetat (DMPA). Yang diberikan secara intramuskuler dan diulang kembali setiap 12 minggu (Sarwono, 2007).

Berdasarkan survei awal yang dilakukan di Kelurahan Pengambiran dari 10 akseptor KB suntik, 7 orang mengatakan mengalami gangguan pola haid diantaraya 3 orang mengalami amenorrea, 3 orang mengalami menoragia, 1 orang mengalami bercak (spotting) dan 3 orang tidak mengalami gangguan siklus menstruasi.

Berdasarkan fenomena di atas, peneleti tertarik untuk melakukan penelitian mengenai Hubungan lama pemakaian kontrasepsi suntik yang mengandung hormon Depo medroxy progesteron asetat (DMPA) dengan gangguan siklus menstruasi di Wilayah Kerja Puskesmas Pagambiran Tahun 2016

\section{SUBJEK DAN METODE PENELITIAN}

\section{Jenis penelitian}

Jenis penelitian yang digunakan adalah jenis penelitian analitik. Desain penelitian cross sectinal, Dimana variable independen (kontrasepsi suntik Depo medroxy progesteron asetat (DMPA) dan variabel dependen (perubahan siklus menstruasi) yang diteliti pada waktu yang bersamaan (Notoatmodjo, 2005). Penelitian ini dilakukan di Puskesmas Pangambiran Kota Padang Tahun 2015, waktu penelitian tanggal 2 Mei - 9 Juli 2016.

\section{Populasi dan Sampel}

\section{Populasi}

Populasi dalam penelitian ini adalah akseptor suntik Depo medroxy progesteron asetat (DMPA) aktif yang berada di di Puskesmas Pagambiran Kota Padang Tahun 2016 berjumlah 113 orang.

2. Sampel

Pengambilan sampel dilakukan dengan cara simple random sampling yang berjumlah 45 orang. Dengan Kriteria menjadi sampel sebagai berikut ;
a. Akseptor suntik Depo medroxy progesteron asetat (DMPA)
b. Bersedia menjadi responden

\section{HASIL DAN PEMBAHASAN}

Variabel pemakaian kontrasepsi suntik dalam hal ini di kategorikan atas 2 kelompok yaitu lama pemakaian alat kontrasepsi suntik yang mengandung hormon Depo medroxy progesteron asetat (DMPA) dengan gangguan siklus menstruasi adapun lama penggunaan kontrasepsi DMPA dapat dilihat pada tabel dibawah ini :

Tabel 1

Distribusi Frekuensi lama pemakaian alat kontrasepsi suntik yang mengandung hormon Depo medroxy progesteron asetat (DMPA) Di Wilayah Kerja Puskesmas Pangambiran Kota Padang Tahun 2015

\begin{tabular}{|c|l|c|c|}
\hline No & \multicolumn{1}{|c|}{$\begin{array}{c}\text { Lama penggunaan } \\
\text { kontrasepsi suntik }\end{array}$} & $\mathbf{f}$ & $\mathbf{\%}$ \\
\hline 1 & Baru & 14 & 31,1 \\
\hline 2 & Lama & 31 & 68,9 \\
\hline & Jumlah & $\mathbf{4 5}$ & $\mathbf{1 0 0}$ \\
\hline
\end{tabular}

Berdasarkan hasil penelitian yang telah dilakukan dari 45 responden sebagian besar responden $68,9 \%$ menggunakan memakai kontrasepsi suntik DMPA sudah lama lebih dari 6 bulan.

Pemakaian kontrasepsi suntik DMPA ini banyak diminati responden karena praktis dan responden cocok dengan pemakaian kontrasepsi suntik ini. Dimana keuntungan dari kontrasepsi suntik ini pencegahan kehamilan jangka panjang, tidak diperlukan pemeriksaan dalam, efek samping sangat kecil, dan tidak mengganggu hubungan seksual (Saifuddin,2008).

Kontrasepsi bagi wanita yang di lakukan melalui suntikan sehingga dapat mencegah kehamilan. Obat ini berisi progesterone yang mempengaruhi pengeluaran hormon dari glandulla pituatari yang mengatur ovulasi dan menyebabkan lender serviks menjadi lebih kental sehingga susah di tembus oleh spermatozoa (BKKBN, 2010).

\section{a. Gangguan Siklus Menstruasi}

Variabel gangguan siklus menstruasi dalam penelitian ini dikategorikan atas 2 kelompok yaitu ada dan tidak ada gangguan siklus menstruasi dapat dilihat pada Tabel 2 berikut :

Tabel 2

Distribusi Frekuensi Gangguan Siklus Menstruasi Di wilayah Kerja Puskesmas Pangambiran Kota Padang Tahun 2015

\begin{tabular}{|c|l|c|c|}
\hline No & \multicolumn{1}{|c|}{$\begin{array}{c}\text { Gangguan Siklus } \\
\text { Menstruasi }\end{array}$} & $\mathbf{f}$ & $\mathbf{\%}$ \\
\hline 1 & Ada & 39 & 86,7 \\
\hline 2 & Tidak ada & 6 & 13,3 \\
\hline & Jumlah & $\mathbf{4 5}$ & $\mathbf{1 0 0}$ \\
\hline
\end{tabular}


Hasil penelitian menunjukkan bahwa lebih dari separoh responden $86,7 \%$ mengalami gangguan siklus menstruasi. Dari $391 \mathrm{bu}$ yang mengalami gangguan mestruasi di ketahui ada sebanyak, 5 orang mengalami menorragia, 6 orang spotting, dan 28 orang mengalami amenorrea.

Kontrasepsi suntik dapat menimbulkan potensi masalah kesehatan reproduksi wanita berhubungan dengan fertilitas yaitu pola menstruasi. Gangguan menstruasi dapat terjadi pada sebagian wanita dari Negara industri maupun Negara berkembang.Gangguangangguan proses menstruasi seperti lamanya siklus menstruasi dapat menimbulkan penyakit kronis. Faktor-faktor yang berhubungan dengan gangguan siklus menstruasi seperti amenorrhea, menorragia dan spotting (Eny Kusmiran,2012).

Hal ini di sebabkan karna hormone progesterone menekan indung telur agar tidak terjadi ovulasi (keluarnya sel telur pada masa subur). Akibat penekanan pada indung telur, maka dapat terjadi gangguan haid. Sebagian besar ibu- ibu akseptor KB suntik DMPA mengalami perubahan pola perdarahan haid sebagai suatu hal yang wajar akibat tubuh ibu menyesuaikan dengan hormone yang terkandung dalam kontrasepsi DMPA yang di masukan ke tubuh ibu sehingga mempengaruhi transport ovum di dalam tuba fallopi

\section{b. Analisa Bivariat}

\section{Hubungan Lama Penggunaan Alat Kontrasepsi DMPA Dengan Gangguan Siklus Menstruasi}

Tabel 3

Distribusi Frekuensi hubungan lama pemakaian alat kontrasepsi suntik yang mengandung hormon Depo medroxy progesteron asetat (DMPA) Dengan Gangguan Siklus Menstruasi Di Wilayah Kerja Puskesmas Pangambiran ota Padang Tahun 2015

\begin{tabular}{|l|c|c|c|c|c|c|}
\hline \multirow{2}{*}{$\begin{array}{c}\text { Lama } \\
\text { penggunaan } \\
\text { kontrasepsi }\end{array}$} & \multicolumn{4}{|c|}{$\begin{array}{c}\text { Gangguan Siklus } \\
\text { Menstruasi }\end{array}$} & \multicolumn{2}{c|}{ Jumlah } \\
\cline { 2 - 7 } & \multicolumn{2}{|c|}{ Ada } & \multicolumn{2}{c|}{$\begin{array}{c}\text { Tidak } \\
\text { ada }\end{array}$} & \multicolumn{2}{|c|}{} \\
\cline { 2 - 7 } & $\mathbf{n}$ & $\mathbf{\%}$ & $\mathbf{n}$ & $\mathbf{\%}$ & $\mathbf{n}$ & \% \\
\hline Baru & 9 & 64,3 & 1 & 3,2 & 14 & 100 \\
\hline Lama & 30 & 96,8 & 5 & 35,7 & 31 & 100 \\
\hline Jumlah & $\mathbf{3 9}$ & $\mathbf{8 6 , 7}$ & $\mathbf{6}$ & $\mathbf{1 3 , 3}$ & $\mathbf{4 5}$ & $\mathbf{1 0 0}$ \\
\hline
\end{tabular}

$$
P=0,008
$$

Hasil penelitian menunjukkan bahwa responden yang mengalami gangguan siklus menstruasi dengan penggunaan kontrasepsi lama sebanyak 30 orang $(96,8 \%)$ lebih banyak di banding responden yang penggunaan kontrasepsi tergolong baru yaitu sebanyak 9 orang $(64,3 \%)$. Hasil uji statistik menggunakan chi square didapatkan nilai $\mathrm{p}=0,008(\mathrm{p}<0,05)$ ini berarti ada hubungan yang bermakna antara lama penggunaan kontrasepsi suntik DMPA dengan gangguan siklus menstruasi.

Jadi, dapat dilihat bahwa gangguan siklus menstruasi memang salah satu efek samping dari kontrasepsi suntik DMPA tetapi gangguan siklus menstruasi tidak hanya karena pemakaian kontrasepsi suntik saja, namun ada faktor - faktor lain dari gangguan siklus menstruasi pada responden misalnya faktor keturunan dan status gizi.

Menurut Hanafi Hartanto (2007) pada pemakaian suntik Depo medroxy progesteron asetat (DMPA), endometrium menjadi dangkal dan atrofis dengan kelenjer- kelenjer yang tidak aktif. Dengan pemakaian jangka lama, endomertium dapat menjadi sedemikian sedikitnya sehingga terjadinya perubahan pola perdarahan haidnya.

Pemakai suntikan depo-provera tidak boleh lebih dari 2 tahun kecuali tidak ada alat kontrasepsi lain yang tepat dan cocok karena dapat menyebabkan perdarahan haidnya terganggu.

Kontrasepsi suntik DMPA sangat efektif tetapi bila mengganggu siklus menstruasi. Sepertiga pemakai KB suntik ini tidak mengalami menstruasi pada 3 bulan setelah suntikan pertama dan sepertiga lainnya mengalami perdarahan tidak teratur dan spotting (bercak perdarahan) selama lebih dari 11 hari setiap bulannya. Semakin lama suntikan KB di pakai, maka lebih banyak wanita yang tidak mengalami menstruasi tetapi lebih sedikit wanita yang mengalami perdarahan tidak teratur. Setelah 2 tahun memakai suntikan KB, sekitar $70 \%$ wanita sama sekali tidak mengalami perdarahan (Hartanto, 2006).

Penelitian ini hampir sama dengan penelitian yang dilakukan oleh Riri Eka Putriyo (2011) didapatkan dari 73 responden yang menggunakan alat kontrasepsi DMPA di Wilayah Kerja Puskesmas Lubuk Buaya terdapat $(63,5 \%)$ yang mengalami gangguan siklus menstruasi. Dari hasil penelitan yang dilakukan oleh Vina (2009) didapatkan bahwa dari 51 responden yang menggunakan alat kontrasepsi DMPA di Kelurahan Seberang Padang didapat $(58,8 \%)$ yang mengalami gangguan siklus menstruasi. 


\section{KESIMPULAN DAN SARAN}

Berdasarkan hasil penelitian diatas dapat disimpulkan sebagai berikut;

a. Sebanyak $68,9 \%$ ibu tergolong lama memakai suntik Depo medroxy progesteron asetat (DMPA)

b. Sebanyak $86,7 \%$ akseptor suntik Depo medroxy progesteron asetat (DMPA) mengalami gangguan siklus menstruasi.

c. Terdapat hubungan yang bermakna antara lama penggunaan kontrasepsi DMPA dengan gangguan siklus menstruasi. $(\mathrm{p}=$ $0,008)$

Saran yang disampaikan untuk penelitian ini; Diharapkan bagi pihak puskesmas menyediakan sarana informasi tentang alat kontrasepsi suntik secara menyeluruh sehingga calon akseptor suntik maupun bukan akseptor suntik dapat memahami tentang segala hal yang berhubungan dengan kontrasepsi suntik, dan diharapkan bagi peneliti selanjutnya dapat melakukan penelitian dengan menggunakan metode penelitian yang lain dan pengambilan sampel yang lebih besar.

\section{DAFTAR PUSTAKA}

Arikunto, Suharsimi. 2009. Manajemen Penelitian, Jakarta : Rineka Cipta.

BKKBN Kota Padang. 2010. Pembinaan PUS dan Kesehatan ber KB, Padang : Perpustakaan BKKBN Kota Padang

Hartanto. 2006. Keluarga Berencana dan Kontrasepsi. Jakarta: Pustaka Sinar Harapan

Kusmiran Eny, 2012. Kesehatan Reproduksi Remaja dan Wanita. Jakarta : Selemba Medika

Notoatmodjo. 2010. Metodelogi penelitian kesehatan, Jakarta : Rineka Cipta

Prawihardjo, Sarwono. 2006. Ilmu kebidanan. Jakarta : YBPSP

Profil Dinas Kesehatan Kota Sumatra Barat, 2010. Laporan Tahunan

Saifuddin, dkk. 2008 . Panduan Praktis Pelayaanan Kontrasepsi, Jakarta : YBPSP

Suratun, dkk 2008. Pelayanan Keluarga Berencana dan Pelayanan Kontrasepsi, Jakarta : Perpustakaan Nasional

Vina, Delani, 2009. Lama pemakaian kontrasepsi suntik DMPA dengan perubahan pola haid akseptor KB di wilayah kerja puskesmas seberang padang tahun 2009 . Akademi kebidanan ranah minang. 